\title{
Small airway remodeling in acute respiratory distress syndrome: a study in autopsy lung tissue
}

\author{
Maina MB Morales ${ }^{1 *}$, Ruy C Pires-Neto ${ }^{1}$, Nicole Inforsato ${ }^{1}$, Tatiana Lanças ${ }^{1}$, Luiz FF da Silva ${ }^{1}$, Paulo HN Saldiva ${ }^{1}$, \\ Thais Mauad ${ }^{1}$, Carlos RR Carvalho ${ }^{2}$, Marcelo BP Amato², Marisa Dolhnikoff ${ }^{1}$
}

\begin{abstract}
Introduction: Airway dysfunction in patients with the Acute Respiratory Distress Syndrome (ARDS) is evidenced by expiratory flow limitation and dynamic hyperinflation. These functional alterations have been attributed to closure/ obstruction of small airways. Airway morphological changes have been reported in experimental models of acute lung injury, characterized by epithelial necrosis and denudation in distal airways. To date, however, no study has focused on the morphological airway changes in lungs from human subjects with ARDS. The aim of this study is to evaluate structural and inflammatory changes in distal airways in ARDS patients.

Methods: We retrospectively studied autopsy lung tissue from subjects who died with ARDS and from control subjects who died of non pulmonary causes. Using image analysis, we quantified the extension of epithelial changes (normal, abnormal and denudated epithelium expressed as percentages of the total epithelium length), bronchiolar inflammation, airway wall thickness, and extracellular matrix (ECM) protein content in distal airways. The Student's t-test or the Mann-Whitney test was used to compare data between the ARDS and control groups. Bonferroni adjustments were used for multiple tests. The association between morphological and clinical data was analyzed by Pearson rank test.

Results: Thirty-one ARDS patients (A: $\mathrm{PaO}_{2} / \mathrm{FiO}_{2} \leq 200,45 \pm 14$ years, 16 males) and 11 controls (C: $52 \pm 16$ years, 7 males) were included in the study. ARDS airways showed a shorter extension of normal epithelium (A:32.9 $\pm 27.2 \%$, $C: 76.7 \pm 32.7 \%, P<0.001$ ), a larger extension of epithelium denudation (A:52.6 $\pm 35.2 \%, C: 21.8 \pm 32.1 \%, P<0.01$ ), increased airway inflammation (A:1(3), C:O(1), $P=0.03$ ), higher airway wall thickness (A:138.7 $\pm 54.3 \mu \mathrm{m}, \mathrm{C}: 86.4 \pm$ $33.3 \mu \mathrm{m}, P<0.01$ ), and higher airway content of collagen I, fibronectin, versican and matrix metalloproteinase-9 (MMP-9) compared to controls $(P \leq 0.03)$. The extension of normal epithelium showed a positive correlation with $\mathrm{PaO}_{2} / \mathrm{FiO}_{2}\left(r^{2}=0.34 ; P=0.02\right)$ and a negative correlation with plateau pressure $\left(r^{2}=0.27 ; P=0.04\right)$. The extension of denuded epithelium showed a negative correlation with $\mathrm{PaO}_{2} / \mathrm{FiO}_{2}\left(r^{2}=0.27 ; P=0.04\right)$.

Conclusions: Structural changes in small airways of patients with ARDS were characterized by epithelial denudation, inflammation and airway wall thickening with ECM remodeling. These changes are likely to contribute to functional airway changes in patients with ARDS.
\end{abstract}

\section{Introduction}

Acute Respiratory Distress Syndrome (ARDS) is characterized by inflammation-mediated alveolar/capillary barrier dysfunction with interstitial and airspace proteinrich edema fluid, resulting in ventilation-perfusion mismatch and consequent severe hypoxemia [1]. Several

\footnotetext{
*Correspondence: maina_morales@yahoo.com.br

'Department of Pathology, Experimental Air Pollution Laboratory-LIM05, Sao Paulo University Medical School, Av Dr. Arnaldo, 455, São Paulo, 01246-903, Brazil

Full list of author information is available at the end of the article
}

ventilatory strategies are implemented in these patients to restore adequate oxygenation; however, mechanical ventilation itself can increase damage to the lung tissue [2]. The inflammatory changes, the loss of airspace capacity secondary to lung collapse and the dynamic reopening of distal lung units during mechanical ventilation, result in a marked decrease in lung compliance. Furthermore, an increase in lung resistance has also been reported, which was partially attributed to impaired peripheral airway function [3]. Studies that report expiratory flow limitation and dynamic

\section{() Biomed Central}


hyperinflation in patients with ARDS also indicate that these functional alterations are related to airway closure [4-7]. Recent studies suggest a role for distal airway epithelium injury in the pathophysiology of human acute lung injury (ALI) and propose that Clara cell CC16 protein levels in plasma and pulmonary edema fluid can be used as a biomarker for the diagnosis of ALI/ARDS [8].

Several experimental models have been proposed to reproduce the functional and morphological lung changes in ARDS. Models of ventilation-induced lung injury have shown that ventilation of normal or lavaged lungs with low end-expiratory lung volume causes a persistent increase in airway resistance and histological evidence of peripheral airway injury characterized by bronchiolar epithelial necrosis and sloughing and rupture of alveolar-bronchiolar attachments [9-13]. These morphological and functional alterations have been mainly attributed to shear stresses caused by cyclic opening and closing of peripheral airways [3,7].

Since airway mechanics is largely dependent on airway structure, extracellular matrix (ECM) composition and distribution, in addition to airway-parenchyma interdependence forces, the functional airway alterations observed in ARDS patients are likely associated with airway morphological changes [14]. Although both human and experimental studies have suggested that airway changes contribute to impaired lung function in acute lung injury, no study to date has focused on distal airway morphological changes in the lungs of human subjects with ARDS. Therefore, the aim of the present study was to analyze the structural and inflammatory changes in small airways of patients with ARDS. For this purpose, we measured the extent of epithelial alterations, airway dimensions and the expression of major lung ECM elements and their regulators within the small airway walls of patients with ARDS submitted to autopsy and compared them with control subjects. We further correlated the airway changes to clinical data and mechanical ventilation parameters.

\section{Materials and methods}

This is a retrospective study using archived material from routine autopsies performed at the Autopsy Service of Sao Paulo University Medical School. The study was approved by the institutional review board for human studies (CAPPesq-FMUSP). Consent for performing autopsy was obtained from the next of kin of all the subjects involved in the study.

\section{Study population}

Thirty-one patients with ARDS submitted to autopsy between 2004 and 2007 were retrospectively included in the study. Inclusion criteria were clinical diagnosis of
ARDS [15], histological findings of diffuse alveolar damage [16], an absence of chronic lung diseases, and sufficient archived autopsy material (at least three small airways per patient) for analyses. ARDS was defined as the 1994 American-European Consensus criteria [15], that is, acute onset, the ratio of arterial oxygen tension to the fraction of inspired oxygen $\left(\mathrm{PaO}_{2} / \mathrm{FiO}_{2}\right) \leq 200$, bilateral infiltrates on chest radiograph and no left atrial hypertension. Twenty-three non-smoker patients who died of non-pulmonary causes, without previous lung diseases were selected for controls. From these, 12 were excluded due to histological lung alterations (bronchopneumonia, pulmonary edema, and pulmonary hemorrhage) and 11 patients with normal lung histology were used as controls. The following clinical data were assessed in medical charts: age, gender, predisposing cause of ARDS, days of ARDS evolution (time interval between ARDS diagnosis and death), and values of $\mathrm{PaO}_{2}$, plateau pressure, positive end-expiratory pressure (PEEP), driving pressure and $\mathrm{PaO}_{2} / \mathrm{FiO}_{2}$.

\section{Tissue processing}

Paraffin blocks of lung tissue collected during autopsy were retrieved from the archives of the Department of Pathology of Sao Paulo University Medical School. In the routine autopsies, three to four fragments of lung tissue were collected from any regions of altered lung parenchyma. In normal lungs, one fragment of lung tissue was collected from each lobe. The tissue had been previously fixed in $10 \%$ buffered formalin for 24 hours, routinely processed and paraffin embedded. Five $\mu \mathrm{m}$ thick sections were stained with hematoxylin and eosin (H\&E) and with Weigert's Resorcin-Fuchsin staining for elastic fibers [17]. The following proteins were identified with immunohistochemistry (IHC) as previously described [18]: collagens type I (COLI) and type III (COLIII), fibronectin, versican and matrix metalloproteinases (MMP) -2 and -9. Antibody types and pre-treatments used are shown in Table 1.

\section{Morphological analysis}

Only transversely cut small airways were analyzed, defined as those showing a short/long diameter ratio greater than 0.6 [19]. Small airways were defined based on their epithelial basement membrane (BM) perimeter (BM perimeter $\leq 6 \mathrm{~mm}$ ) $[19,20]$. Airways were subdivided into epithelial layer, inner layer (located between the epithelium and the internal smooth muscle border), smooth muscle (SM), and outer layer (located between the external SM border and the alveolar parenchyma) (Figure 1) [19]. In each airway, the entire circumference was analyzed at a $400 \times$ magnification by an investigator blinded to the study group. Measurements were taken using image analysis with the software Image-Pro ${ }^{\circledR}$ Plus 
Table 1 Antibodies and processing used in immunohistochemical analyses

\begin{tabular}{cccccc}
\hline Antibody & Pre-treatment & Specie & Clone & Dilution & Origin \\
\hline Collagen I & Citrate & Goat & Polyclonal & $1: 1000$ & US Biological-Swampscott, Massachusetts/USA \\
Collagen III & Trypsin & Mouse & III-53 & $1: 100$ & Oncogene \& Calbiochem, Darmstadt/Germany \\
Fibronectin & Citrate & Rabbit & Polyclonal & $1: 6000$ & Dako, Glostrup/Denmark \\
Versican & Trypsin & Mouse & 2-B-1 & $1: 100$ & Seikagaku CO, Tokyo/Japan \\
MMP-2 & Citrate & Mouse & A-Gel VC2 & $1: 3000$ & LabVision, Fremont/USA \\
MMP-9 & Citrate & Mouse & 56-2A4 & $1: 50$ & Calbiochem, Darmstadt/Germany \\
\hline
\end{tabular}

MMP, matrix metalloproteinase.

4.1 for Windows ${ }^{\circledR}$ (Media Cybernetics-Silver Spring, MD, USA) on a personal computer connected to a digital camera coupled to a microscope (Leica DMR, Leica Microsystems Wetzlar GmbH, Wetzlar, Germany).

The following parameters were analyzed on H\&E stained slides: 1) the extent of normal epithelium, abnormal epithelium (epithelial cells with histological signs of necrosis and/or degeneration) and denudated epithelium (BM exposed) expressed as a percent of the total epithelium length; 2) thickness of the inner, SM and outer airway layers and the total airway wall expressed as layer area corrected by the corresponding $\mathrm{BM}$ perimeter $\left(\mu \mathrm{m}^{2} / \mu \mathrm{m}\right)$; and 3) inflammation index determined semiquantitatively based on the presence of inflammatory cells infiltrating the airway wall, using a four-grade scale: absent $=0$, minimal inflammation $=1$, moderate inflammation $=2$ and marked inflammation $=3$ [13].

The content of ECM proteins and MMPs was determined in IHC-stained slides. The area of ECM proteins positive staining was determined in three airway regions: inner, SM and outer layers. The area of MMP-positive staining was determined in two airway regions: epithelial layer and total airway wall (including the inner and outer layers and SM together). Protein content was expressed as positive area divided by airway BM length $\left(\mu \mathrm{m}^{2} / \mu \mathrm{m}\right)$.

\section{Clinical-morphological correlations}

Since lung injury can be observed after a few hours of mechanical ventilation [12], we investigated the possible association of morphological airway changes with mechanical ventilation and disease severity in ARDS patients who died within 48 hours after the diagnosis $(n=16)$. For this purpose we correlated the morphological parameters with ventilatory parameters (mean values of plateau pressure, driving pressure and PEEP) and $\mathrm{PaO}_{2} / \mathrm{FiO}_{2}$ value obtained at the moment of the clinical diagnosis.

\section{Statistical analysis}

Data are presented as mean \pm SD or median (interquartile range). After testing for distribution of data, the Student's $t$-test or the Mann-Whitney test were used to

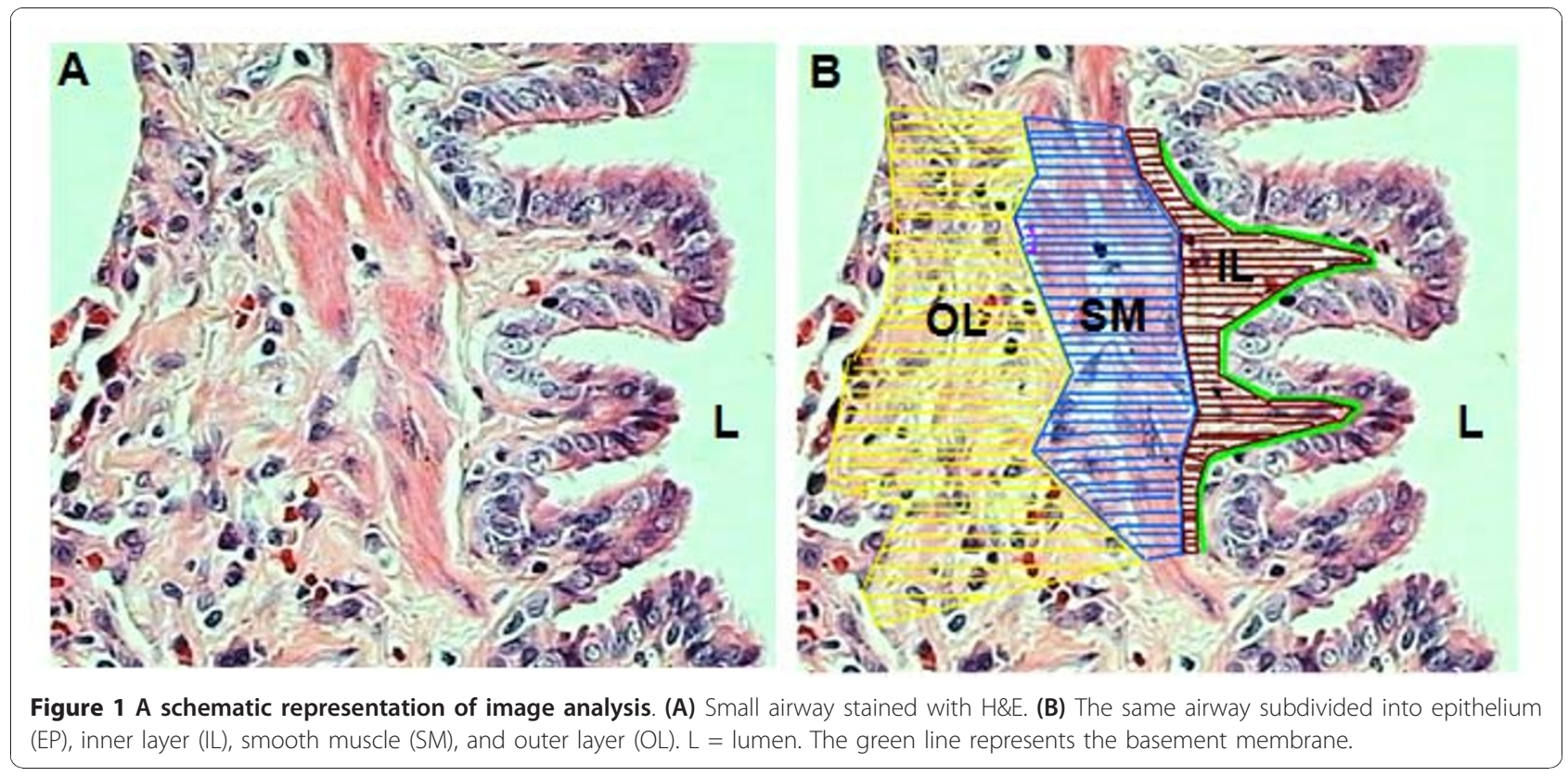


compare data between the ARDS and control groups. Bonferroni adjustments were used for multiple tests. The association between morphological and clinical data was analyzed by Pearson rank test. Statistical analysis was performed using the statistical package SPSS 15.0 (SPSS, Chicago, IL, USA). The level of significance was set at $P<0.05$.

\section{Results}

\section{Study population}

Demographic and clinical data of ARDS patients $(n=31)$ and controls $(n=11)$ are presented in Table 2. The mean \pm SD age of ARDS patients and controls was $45 \pm 14$ and $52 \pm 16$ years, respectively $(P=0.18)$. The main predisposing factors for ARDS were pneumonia (42\%) and sepsis (35\%). Pulmonary ARDS (ARDSp) and extrapulmonary ARDS (ARDSext) accounted for 52\% $(n=16)$ and $48 \%(n=15)$ of the patients, respectively. These two subgroups were also similar with respect to age $($ ARDSp $=45.9 \pm 13.6$ years and ARDSext $=43.6 \pm$ 4.3) and gender (ARDSp $=7 \mathrm{~F} / 9 \mathrm{M}$ and $\mathrm{ARDSext}=8$ F/7 M). Days of ARDS evolution (time interval between ARDS diagnosis and death) ranged from 1 to 24; however, most patients $(71 \%)$ died in the first week, and $52 \%$, within the first 48 hours (Table 3). Ventilatory parameters and $\mathrm{PaO}_{2} / \mathrm{FiO}_{2}$ values of ARDS patients are presented in Table 3. Median values of plateau pressure, PEEP and driving pressure were $28(10) \mathrm{cmH}_{2} \mathrm{O}, 11(8)$ $\mathrm{cmH}_{2} \mathrm{O}$ and 15(5) $\mathrm{cmH}_{2} \mathrm{O}$, respectively. All patients were ventilated using a lung-protective strategy with a low tidal volume $(\leq 6 \mathrm{~mL} / \mathrm{Kg})$. Control patients did not receive mechanical ventilation. One control subject died at home, seven controls arrived at the emergency room in cardiorespiratory arrest and three controls were admitted to the hospital for non-pulmonary conditions. All control patients were submitted to resuscitation maneuvers for a maximum of one hour. All control patients were non-smokers.

\section{Morphological analysis}

All available transversely cut small airways for each patient were analyzed, varying from three to six airways per patient (mean of 3.6 per patient in each staining). A total of 1,218 airways were analyzed considering all the stainings used. The median perimeter of small airways for ARDS patients and controls was 1.94(1.13) mm and 2.06(1.21) $\mathrm{mm}$, respectively, corresponding to small membranous bronchioles [21]. There was no significant difference in airway perimeter between ARDS patients and controls.

Structural and inflammatory data are presented in Table 4 and Figure 2 . There was a significantly lower extent of normal epithelium $(P<0.001)$ and a higher extent of abnormal epithelium $(P=0.007)$ and epithelial
Table 2 Clinical data of Acute Respiratory Distress Syndrome (ARDS) patients and controls

\begin{tabular}{|c|c|c|}
\hline Characteristics & ARDS & Controls \\
\hline Number & 31 & 11 \\
\hline Age (years) ${ }^{\alpha}$ & $44(20)$ & $48(25)$ \\
\hline Gender (M/F) & $16 / 15$ & $7 / 4$ \\
\hline Predisposing factor for ARDS, $\mathrm{n}(\%)$ & & NA \\
\hline Pneumonia & $13(42)$ & \\
\hline Sepsis & $11(35)$ & \\
\hline Aspiration & $2(6)$ & \\
\hline Pancreatitis & $2(6)$ & \\
\hline Hypovolemic shock & $2(6)$ & \\
\hline Alveolar bleeding & $1(3)$ & \\
\hline \multicolumn{3}{|l|}{ Co-morbidities, n (\%) } \\
\hline Systemic arterial hypertension & $9(20)$ & $6(54)$ \\
\hline Chronic hepatopathy & $9(20)$ & $1(9)$ \\
\hline AIDS & $8(17)$ & - \\
\hline Diabetes mellitus & $5(11)$ & $3(27)$ \\
\hline Systemic Lupus Erythematosus & $3(6.5)$ & - \\
\hline Pneumocystosis & $3(6.5)$ & - \\
\hline Pulmonary hypertension & $1(2.2)$ & - \\
\hline Multiple sclerosis & $1(2.2)$ & - \\
\hline Multiple myeloma & $1(2.2)$ & - \\
\hline Crohn disease & $1(2.2)$ & - \\
\hline Chagas disease & $1(2.2)$ & $1(9)$ \\
\hline Schistosomosis & $1(2.2)$ & - \\
\hline Acute myeloid leukemia & $1(2.2)$ & - \\
\hline Lymphoma & $1(2.2)$ & - \\
\hline Tuberculosis & $1(2.2)$ & - \\
\hline Epilepsy & - & $1(9)$ \\
\hline \multicolumn{3}{|l|}{ Primary Cause of Death, n (\%) } \\
\hline Multiorgan failure & $14(45)$ & \\
\hline Refractory sepsis & $7(23)$ & \\
\hline Respiratory failure & $4(13)$ & \\
\hline Thoracic bleeding & $2(6)$ & \\
\hline Gastrointestinal bleeding & $4(13)$ & $1(9)$ \\
\hline Cardiovascular diseases & & $9(82)$ \\
\hline Vesical bleeding & & $1(9)$ \\
\hline Total length hospitalization, days & $15(19)$ & $0(0.08)$ \\
\hline
\end{tabular}

Data are given as median (interquartile range) or $\mathrm{n}$ (percentage).

$M$, masculine; F, feminine; AIDS, acquired Immunodeficiency Syndrome; NA, non applicable.

denudation $(P=0.015)$ in the ARDS group compared to controls. The ARDS group showed a significantly higher thickness of the total airway wall, inner layer and outer layer compared to controls $(P \leq 0.03)$. The inflammation index was also higher in ARDS patients than in controls $(P=0.03)$.

Immunoreactivity of ECM components and MMPs showed similar patterns of distribution in the lung tissue of both ARDS patients and controls. MMPs showed positive staining mainly in inflammatory cells (mostly monocytes/macrophages and PMNs) and weak 
Table 3 Days of evolution, ventilatory parameters and $\mathrm{PaO}_{2} / \mathrm{FiO}_{2}$ values of Acute Respiratory Distress Syndrome (ARDS) patients

\begin{tabular}{|c|c|c|c|c|c|}
\hline Patient & Days of ARDS & Plateau pressure ${ }^{\alpha}$ & PEEP $^{\alpha}$ & Driving pressure ${ }^{\alpha}$ & $\mathrm{PaO}_{2} / \mathrm{FiO}_{2}$ \\
\hline 1 & 1 & 18 & 08 & 10 & 161.0 \\
\hline 2 & 1 & 35 & 20 & 15 & 93.2 \\
\hline 3 & 1 & 12 & 06 & 06 & 170.7 \\
\hline 4 & 1 & 28 & 14 & 12 & 82.0 \\
\hline 5 & 1 & 21 & 9 & 12 & 93.7 \\
\hline 6 & 1 & 25 & 10 & 15 & 68.1 \\
\hline 7 & 1 & 30 & 08 & 22 & 79.5 \\
\hline 8 & 1 & 40 & 10 & 30 & 47.2 \\
\hline 9 & 1 & 40 & 15 & 25 & 51.0 \\
\hline 10 & 2 & 25 & 10 & 15 & 166.3 \\
\hline 11 & 2 & 32 & 22 & 10 & 137.3 \\
\hline 12 & 2 & 35 & 17 & 18 & 104.2 \\
\hline 13 & 2 & 28 & 13 & 15 & 133.5 \\
\hline 14 & 2 & 23 & 08 & 15 & 130.8 \\
\hline 15 & 2 & 27 & 14 & 13 & 156.5 \\
\hline 16 & 2 & 21 & 11 & 10 & 111.7 \\
\hline 17 & 3 & 38 & 18 & 20 & 84.0 \\
\hline 18 & 3 & 30 & 14 & 16 & 166.2 \\
\hline 19 & 4 & 25 & 11 & 14 & 197.0 \\
\hline 20 & 6 & 21 & 09 & 12 & 149.7 \\
\hline 21 & 6 & 25 & 10 & 15 & 196.7 \\
\hline 22 & 7 & 21 & 07 & 14 & 189.7 \\
\hline 23 & 8 & 28 & 11 & 17 & 126.3 \\
\hline 24 & 9 & 29 & 17 & 12 & 119.7 \\
\hline 25 & 10 & 30 & 14 & 16 & 108.3 \\
\hline 26 & 13 & 22 & 09 & 13 & 153.2 \\
\hline 27 & 14 & 28 & 17 & 11 & 195.6 \\
\hline 28 & 16 & 20 & 10 & 10 & 186.7 \\
\hline 29 & 19 & 39 & 18 & 21 & 199.0 \\
\hline 30 & 22 & 25 & 14 & 11 & 182.4 \\
\hline 31 & 24 & 37 & 20 & 17 & 173.7 \\
\hline Median (IQR) & $2(8)$ & $28(10)$ & $11(8)$ & $15(5)$ & $137(80)$ \\
\hline
\end{tabular}

$\mathrm{PaO}_{2} / \mathrm{FiO}_{2}$, ratio of arterial oxygen tension to the fraction of inspired oxygen.

PEEP, positive end-expiratory pressure.

For each patient, plateau pressure and PEEP correspond to mean values in the first 48 hours.

$\mathrm{PaO}_{2} / \mathrm{FiO}_{2}$ correspond to values assessed at the time of clinical diagnosis.

${ }^{\alpha} \mathrm{CmH}_{2} \mathrm{O}$.

expression in airway epithelial cells and SM cells. Representative photomicrographs of airway ECM and MMP-9 expression are shown in Figure 3. Figure 4 shows protein content in ARDS patients and controls. We observed higher content of COL I, fibronectin and versican in the outer airway layer of ARDS patients compared to controls $(P \leq 0.03)$. Versican expression was also higher in the inner airway layer in ARDS patients $(P<0.02)$. There were no differences in COL III and elastic fiber content between the two groups, and no difference in the content of ECM proteins within the SM layer. We observed increased expression of MMP-9 in the ARDS group only in the airway wall $(P=0.003)$, with no differences observed within the epithelial layer. There were no differences in MMP-2 expression between the two groups.

Comparisons between ARDSp and ARDSext subgroups showed higher levels of MMP-9 in the airways from the ARDSp group $(P=0.03)$. There were no significant differences in the inflammation index or in any structural parameter between the two subgroups. To evaluate the airway inflammation and structural changes over the course of the disease, we also categorized our ARDS patients into two subgroups according to time 
Table 4 Structural and inflammatory data on small airways in ARDS patients and controls

\begin{tabular}{cccc}
\hline & ARDS & Controls & $\boldsymbol{P}$ \\
\hline Normal epithelium & $32.9 \pm 27.2$ & $76.7 \pm 32.7$ & $<0.001$ \\
Abnormal epithelium & $14.4 \pm 14.8$ & $1.37 \pm 3.20$ & 0.007 \\
Denudated epithelium & $52.6 \pm 35.2$ & $21.8 \pm 32.1$ & 0.015 \\
Airway wall thickness & $138.7 \pm 54.3$ & $86.4 \pm 33.3$ & 0.005 \\
Inner layer thickness & $35.2 \pm 32.0$ & $17.2 \pm 8.14$ & 0.034 \\
Smooth Muscle thickness & $14.8 \pm 8.20$ & $18.5 \pm 22.7$ & 0.427 \\
Outer layer thickness & $88.7 \pm 29.9$ & $50.4 \pm 17.7$ & $<0.001$ \\
Inflammation index [median(range)] & $1(3)$ & $0(1)$ & 0.027 \\
\hline
\end{tabular}

ARDS, acute respiratory distress syndrome.

Values are expressed as mean \pm SD, unless otherwise specified. Epithelium parameters are expressed as a percentage of the airway basement membrane perimeter (\%). Airway layers are presented as area $\left(\mu \mathrm{m}^{2}\right)$ corrected by the basement membrane perimeter $(\mu \mathrm{m})$ interval between ARDS diagnosis and death, as follows: Ards $1=1$ to 6 days (21 patients) and Ards $2=\geq 7$ days (11 patients). We did not find any significant differences in inflammatory or structural parameters between the two subgroups.

\section{Clinical-morphological correlations}

The extension of normal epithelium showed a significant positive correlation with $\mathrm{PaO}_{2} / \mathrm{FiO}_{2}\left(\mathrm{r}^{2}=0.34 ; P=0.018\right)$ and a negative correlation with plateau pressure $\left(\mathrm{r}^{2}=0.27 ; P=0.039\right)$ (Figure 5$)$. In addition, the extension of denuded epithelium showed a negative correlation with $\mathrm{PaO}_{2} / \mathrm{FiO}_{2}\left(\mathrm{r}^{2}=0.27 ; P=0.038\right)$. There was no correlation between values of PEEP or driving pressure and the morphological parameters.

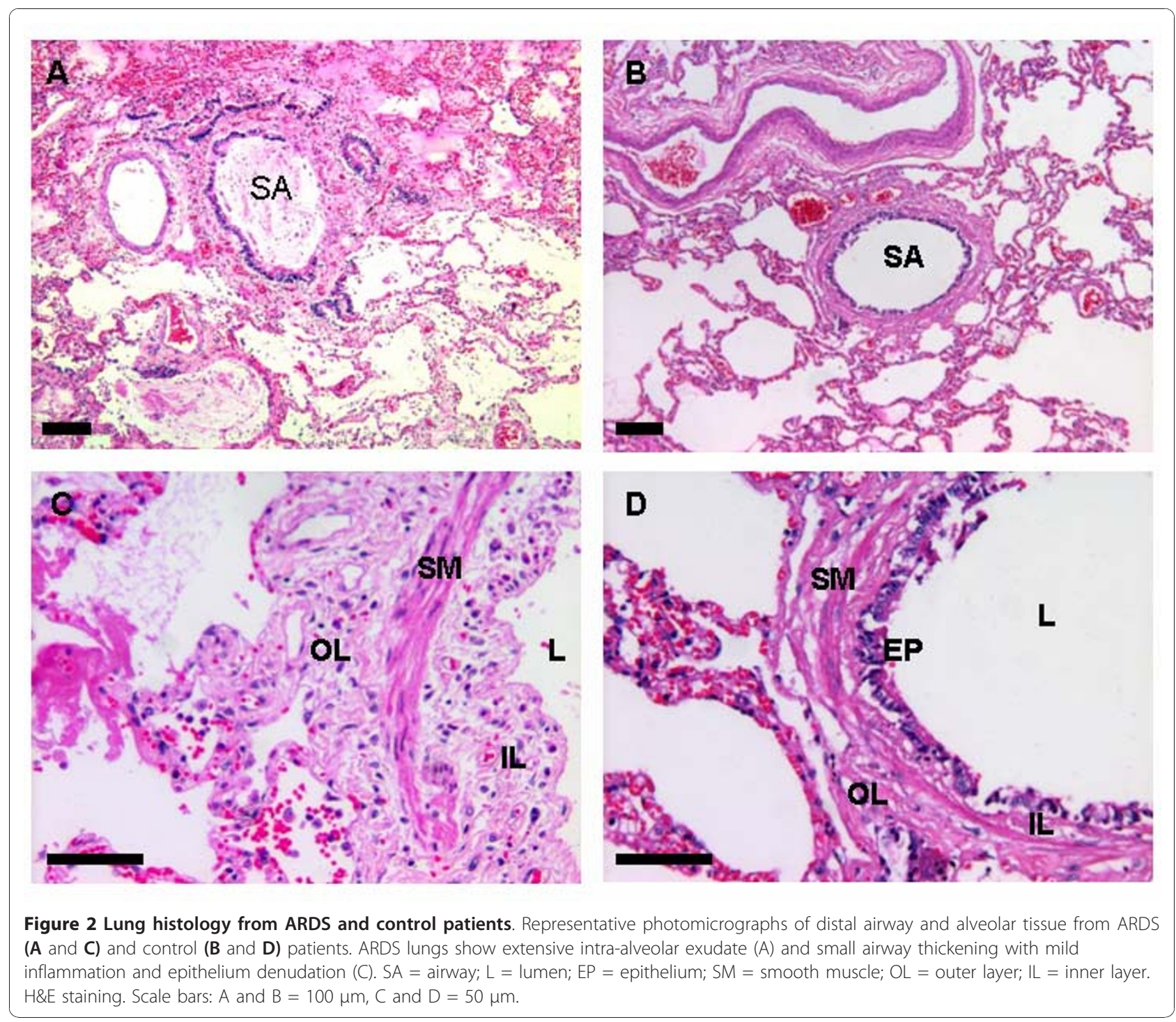



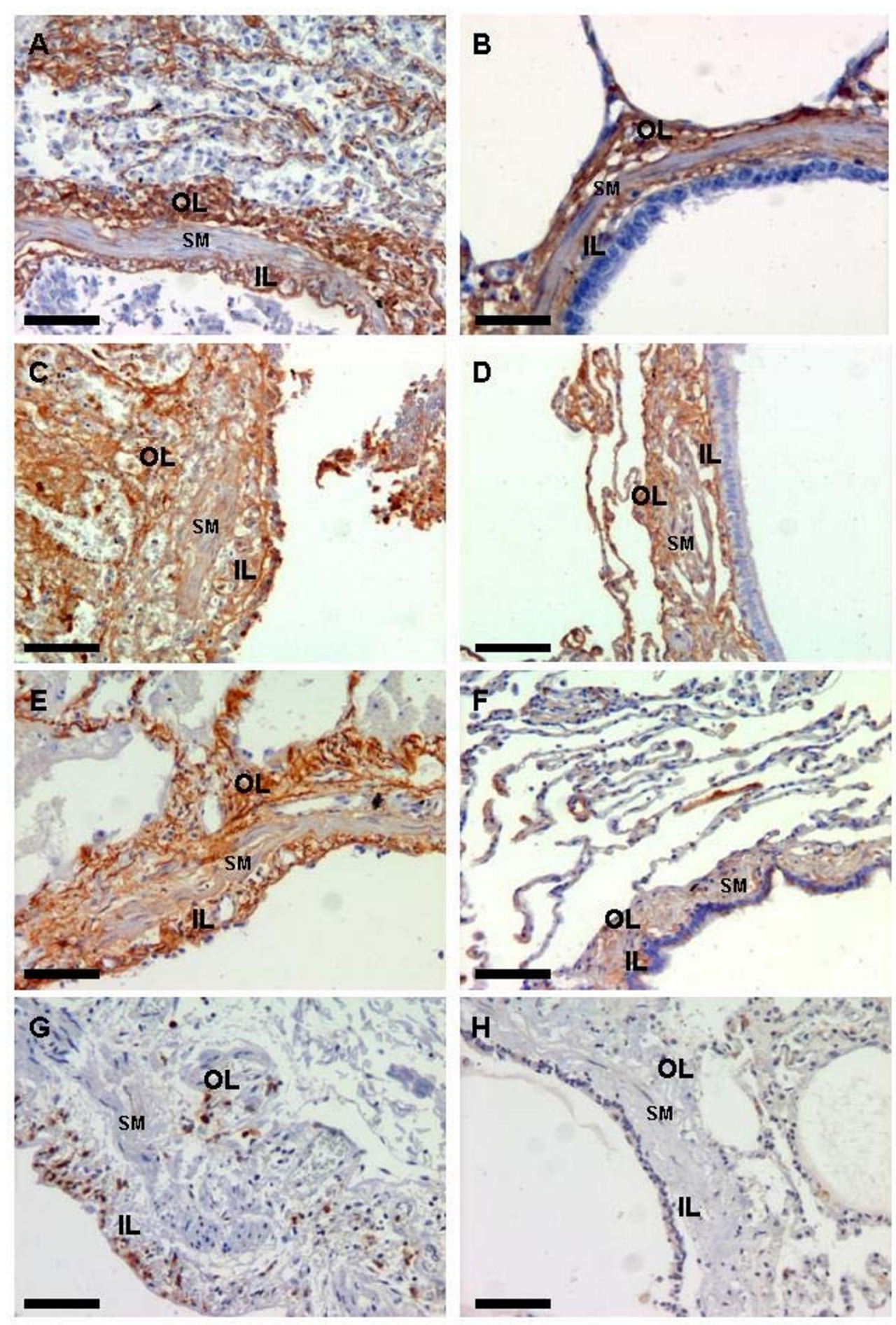

Figure 3 Representative photomicrographs of extracellular matrix proteins and matrix metalloproteinase-9 expression in the airways. Photomicrographs of small airways from ARDS patients $(\mathbf{A}, \mathbf{C}, \mathbf{E}, \mathbf{G})$ and controls $(\mathbf{B}, \mathbf{D}, \mathbf{F}, \mathbf{H})$ stained with anti-collagen I (A and B), anti-fibronectin (C and D), anti-versican ( $E$ and F) and anti-MMP-9 (G and H). ARDS airways show higher content of collagen I, fibronectin and versican and higher MMP-9 expression by inflammatory cells. $\mathrm{L}=$ lumen; $\mathrm{SM}=$ smooth muscle; $\mathrm{OL}=$ outer layer; $\mathrm{IL}=$ inner layer. Scale bars $=50 \mu \mathrm{m}$. 


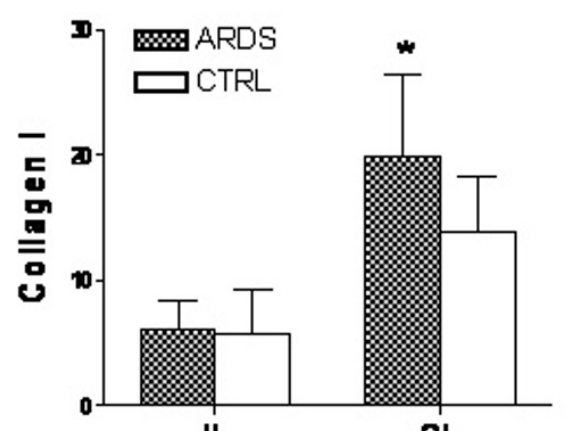

IL

OL

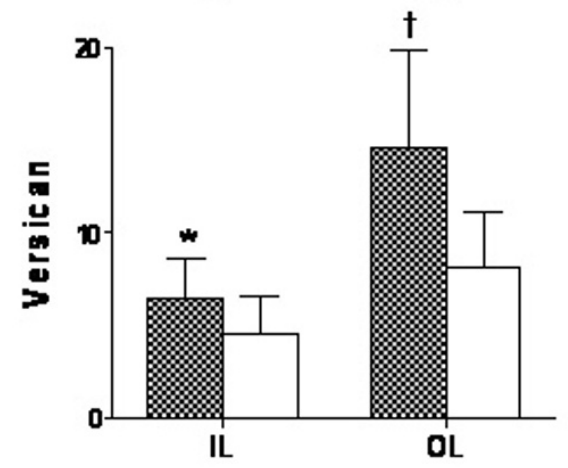

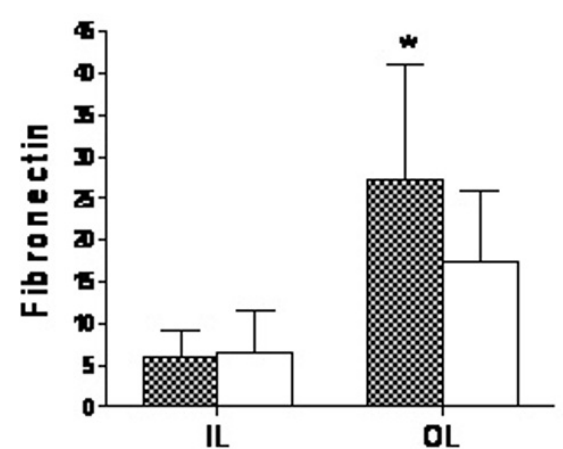

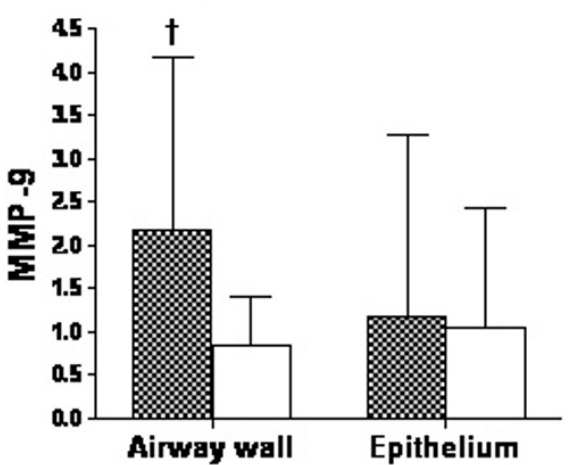

Figure 4 Protein content in ARDS patients and controls. The graphs show collagen I, fibronectin, versican and MMP-9 content ( $\left.\mu \mathrm{m}^{2} / \mu \mathrm{m}\right)$ in the small airways of ARDS patients and controls. IL $=$ inner layer, $\mathrm{OL}=$ outer layer. Bars represent mean; lines represent $\mathrm{SD}$. ${ }^{*} P \leq 0.03$ compared with controls; $+P<0.003$ compared with controls.

\section{Discussion}

In the present study, we analyzed for the first time the structural changes in small airways in patients with ARDS compared to control subjects. Our main findings were the presence of epithelial denudation, airway inflammation and increased thickness of small airway walls with deposition of collagen I, fibronectin and versican, mainly localized to the outer wall.

Recent studies have suggested that the peripheral airways play an important role in the pathophysiology of ALI/ARDS [3]; however, no study has focused on airway morphological changes in lungs from human subjects
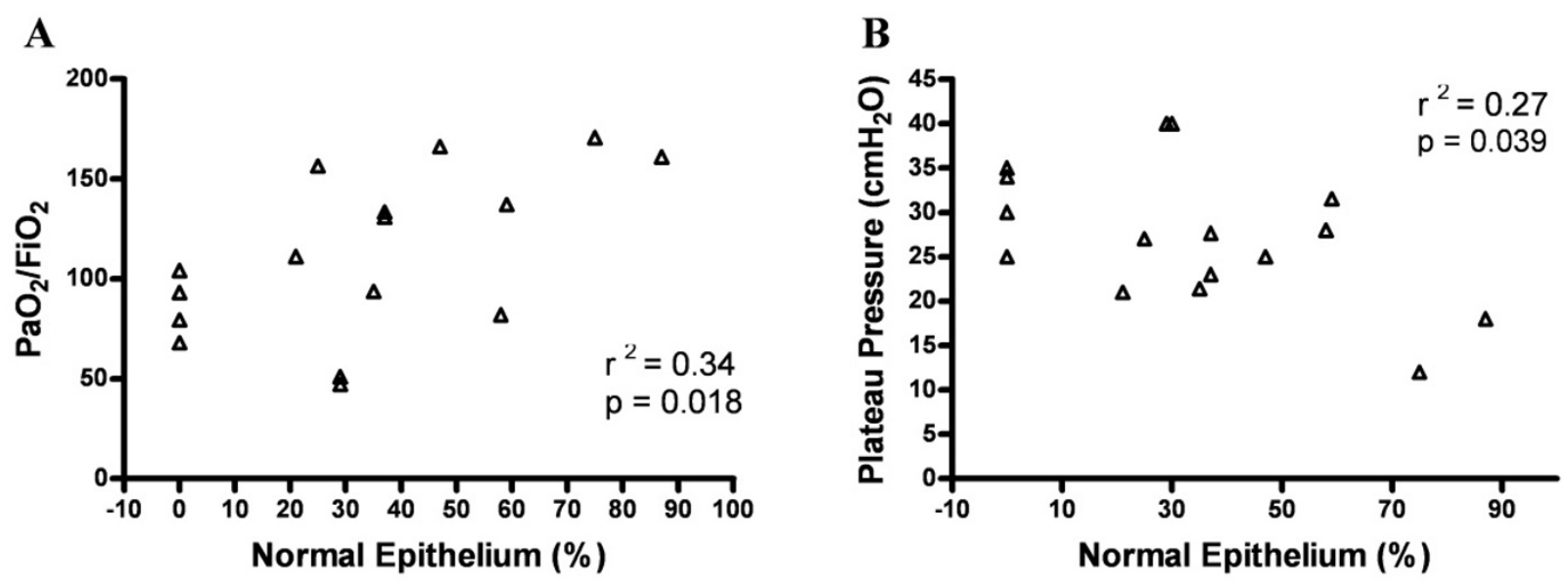

Figure 5 Clinical-morphological correlations in ARDS patients. The graphs show the correlation (Pearson test) between epithelial morphological changes and $\mathrm{PaO}_{2} / \mathrm{FiO}_{2}$ (A) and plateau pressure (B) in patients who died within 48 hours after the clinical diagnosis $(n=16)$. 
with ARDS. Experimental models of ALI are used to investigate these changes and have shown epithelial necrosis and denudation in distal airways of animals ventilated with low lung volumes [9-12]. Our results are in line with these experimental studies and show that bronchiolar epithelium denudation is also present in humans and is associated with ARDS severity. The mechanisms of epithelial injury and denudation are not completely understood but are likely to result from changes in shear stress due to reopening of either collapsed small airways or non-collapsed flooded airways $[7,22]$ and from stretch-induced hyperdistension of epithelial cells [23]. Gadigliali and Gaver (2008) suggested that this increased stress on the airway epithelial cell lining may induce significant cellular deformations, cell death, and/or disruption of cell adhesions. The damaged epithelial cell may in turn upregulate inflammatory pathways and/or alter surfactant secretion [24].

Airway inflammation is diffusely present in surfactantdepleted lungs of rabbits submitted to low end-expiratory lung volume ventilation [13] and in rats submitted to high volume-induced lung injury [23]. Our results show that distal airway inflammation is also present in human ARDS lungs. Whether airway inflammation in ARDS represents a response of terminal bronchioles to the primary insult or is rather a spreading of inflammatory cells from the alveolar tissue is not clear. In either case we suggest that airway inflammation is likely to be involved in the pathogenesis of airway remodeling in ARDS.

Previous studies evaluating ECM changes in ARDS have shown altered alveolar septa with lung fibrosis [25] and increased alveolar content of collagen and elastic fibers [26-28], fibronectin [29] and versican [30] in exudative and/or proliferative phases of lung injury. The fibroproliferative process characterized by collagen deposition, even in the early phase of ARDS, is associated with a severe reduction in respiratory system compliance [31]. We show for the first time that remodeling is also present at the terminal bronchiolar level and suggest that these structural airway changes may also have functional implications. The functional consequences of airway remodeling are dependent on which layer in the airway wall is changed as well as on the composition and mechanical properties of the material that is altered [32]. The inner area provides resistance of the tissue to compression; the smooth muscle layer is usually altered in pulmonary diseases characterized by bronchoconstriction; and the outer wall is directly attached to the lung parenchyma and is, therefore, crucial for the maintenance of lung tissue structure and transmission of elastic forces. Thus, we believe that airway compartmentalization provides important insight toward a better understanding of structure-function relationships in pulmonary diseases. Airway dysfunction in patients with ARDS who are ventilated with low PEEP is characterized by expiratory flow limitation and gas trapping [4,5], which have been related to airway closure and inhomogeneous distribution of ventilation $[6,7]$. The mechanisms involved in airway closure include surfactant dysfunction and a decrease in airway-parenchyma interdependence secondary to interstitial edema, alveolar collapse, and possibly the rupture of alveolar attachments $[3,11,12]$. Since the outer airway layer is the main region where mechanical forces are transmitted from the alveolar parenchyma to the airway wall, it represents a critical site that may be affected by both the inflammatory process and the mechanical damage caused by abnormal stress. Interestingly, in this study collagen I, fibronectin and versican levels were primarily increased in the outer airway wall, which could contribute to airway-parenchyma uncoupling by altering the mechanical interdependence between these two compartments.

The higher MMP-9 expression seen in the ARDS group is in accordance with previous studies showing increased levels of MMP-9 in the bronchoalveolar lavage of patients with ARDS [33,34]. The observation of increased MMP-9 expression in inflammatory cells within the airway wall suggests that MMP-9 may be involved in airway ECM remodeling in ARDS patients. Increased MMP-9 expression could either be associated with higher ECM turnover within the airway wall or represent a response to excessive matrix deposition in an attempt to restore equilibrium to the ECM composition.

In chronic airway inflammatory lung diseases, airway remodeling is correlated with marked changes in airway mechanics and symptoms related to airway obstruction [14]. Although airway obstruction is not a characteristic of ALI, patients who survive ARDS can present mild to moderate abnormalities in lung function evidenced by decreased $\mathrm{FEV}_{1}, \mathrm{FVC}$ and/or $\mathrm{FEV}_{1} / \mathrm{FVC}$ evaluated one to three years after hospital discharge [35-37]. It is possible that the persistence of these pulmonary function changes is related to airway remodeling.

To determine if the airway changes were different in patients with distinct predisposing factors, ARDS patients were divided into pulmonary and extrapulmonary subgroups. Although we observed higher levels of MMP-9 in the airways from the ARDSp subgroup, there were no differences in the inflammation index or in any structural parameter between the ARDSp and ARDSext subgroups. These findings suggest that the airway alterations in ARDS were the result of the inflammatory insult (and/or ventilator injury), independent of the primary cause. We also categorized our ARDS patients 
into two subgroups according to time interval between ARDS diagnosis and death. We did not find any significant differences in inflammatory or structural parameters between patients who died in the first week and patients who died more than seven days after diagnosis, suggesting that the airway alterations were present at the start of the syndrome and were maintained over time.

Pulmonary injury is heterogeneously distributed in ARDS, resulting in inhomogeneous ventilation and predisposing the lung to ventilator-induced lung injury [2]. Previous studies suggest that lung injury in ALI is more severe in the atelectatic dependent lung regions $[38,39]$; however, more recent studies have suggested that the peripheral airway injury observed in experimental ALI is diffusely distributed in both dependent and non-dependent regions [13]. One limitation of our study was the retrospective analysis of lung tissue, which did not allow us to systematically assess regional differences in airway injury in these lungs from human subjects with ARDS. Due to the retrospective character of the study, another limitation was the lack of systematic recording of clinical data. In many charts, information regarding smoking habits or the specifics of the lung mechanics was not available, which could have influenced the interpretation of our results. Furthermore, since we only analyzed tissue from patients who died, the extent to which the results obtained in the present study can be transposed to the less severe cases of ARDS is unclear.

Although the observed airway changes are likely to play a role in the pathogenic mechanisms of ALI, it is not clear if these changes are due to the insult leading to ARDS or to ventilator injury. It is well known that pulmonary injury in ARDS patients can be exacerbated by the ventilatory strategy [2], as indicated by clinical trials showing significantly higher mortality among patients who received ventilation with high tidal volume and high inspiratory plateau pressures [40-42]. In our patients, airway epithelial injury showed significant correlations with $\mathrm{PaO}_{2} / \mathrm{FiO}_{2}$ and inspiratory pressure values, suggesting that both the primary pulmonary insult leading to ARDS and the ventilator injury are associated with airway structural alterations in ARDS patients. Rouby et al. [43] analyzed the histological aspects of pulmonary barotrauma in critically ill patients with acute respiratory failure and observed in 6 out of 30 lungs severe damage to terminal bronchioles characterized by bronchiolar dilation, epithelial hyperplasia and metaplasia. Similarly to our results, the authors suggested that mechanical ventilation with a high peak airway pressure plays a role in the pathogenesis of bronchial injury and airspace enlargement.

\section{Conclusions}

Our results revealed structural changes in the small airways of patients with ARDS, characterized by epithelial denudation, inflammation and airway wall thickening with ECM remodeling. These small airway alterations are likely to contribute to impaired lung function in patients with ARDS.

\section{Key messages}

- Patients with ARDS show evidence of airway dysfunction characterized by expiratory flow limitation and dynamic hyperinflation. These functional alterations have been attributed to closure/obstruction of small airways. Airway morphological changes have been reported in experimental models of acute lung injury, characterized by epithelial necrosis and denudation in distal airways.

- In the present study, we analyzed for the first time the structural changes in distal airways in ARDS patients, which were characterized by epithelial denudation, inflammation and airway wall thickening with extracellular matrix remodeling.

- These small airway alterations are likely to contribute to impaired lung function in patients with ARDS.

\section{Abbreviations}

ALI: acute lung injury; ARDS: acute respiratory distress syndrome; BM: basement membrane; COLI: collagen type I; COLIII: collagen type III; ECM: extracellular matrix; H\&E: hematoxylin and eosin; IHC: immunohistochemistry; MMP: matrix metalloproteinases; $\mathrm{PaO}_{2} / \mathrm{FiO}_{2}$ : ratio of arterial oxygen tension to the fraction of inspired oxygen; PEEP: positive end-expiratory pressure; SM: smooth muscle.

\section{Acknowledgements}

MMBM received a fellowship from Fundação de Amparo à Pesquisa do Estado de São Paulo (FAPESP). PHNS, TM, MBPA and MD receive individual research grants from Conselho Nacional de Desenvolvimento Científico e Tecnológico (CNPq). The study was supported by Laboratório de Investigação Médica-LIM05 do Hospital das Clinicas da Faculdade de Medicina da Universidade de São Paulo (LIMHC-FMUSP).

\section{Author details}

'Department of Pathology, Experimental Air Pollution Laboratory-LIM05, Sao Paulo University Medical School, Av Dr. Arnaldo, 455, São Paulo, 01246-903, Brazil. ${ }^{2}$ Pulmonary Division, Heart Institute (InCor), Sao Paulo University Medical School, Av Dr Enéas Carvalho de Aguiar, 44, São Paulo, 05403-904, Brazil.

\section{Authors' contributions}

MMBM participated in the design of the study, carried out the immunohistochemistry reactions and the morphometric analyses, performed the statistical analysis and drafted the manuscript. RCPN and NI helped to carry out the morphometric analyses and were involved in drafting the manuscript. TL helped to carry out the morphometric analyses, was involved in the acquisition of clinical data and was involved in revising the manuscript. LFFS participated in the design of the study, performed the histological analysis and the immunohistochemistry quality control, helped at the statistical analysis and was involved in drafting the manuscript. PHNS and TM contributed to the conception and design of the study and were involved in drafting the manuscript. CRRC and MBPA contributed to the conception and design of the study, contributed to analysis and 
interpretation of data and were involved in revising the manuscript. MD conceived the study, performed the histological analysis, performed the immunohistochemistry quality control, performed the statistical analysis, drafted and revised the manuscript. All authors read and approved the final version of the manuscript.

\section{Competing interests}

The authors declare that they have no competing interests.

Received: 18 May 2010 Revised: 13 September 2010

Accepted: 6 January 2011 Published: 6 January 2011

\section{References}

1. Ware $L B$, Matthay MA: The acute respiratory distress syndrome. N Engl J Med 2000, 342:1334-1349.

2. Tremblay NL, Slutsky AS: Ventilator-induced lung injury: from the bench to the bedside. Intensive Care Med 2006, 32:24-33.

3. Jain M, Sznajder J: Peripheral airways injury in acute lung injury/acute respiratory distress syndrome. Current Opinion in Critical Care 2008 14:37-43.

4. Koutsoukou A, Armaganidis A, Stavrakaki-Kallergi C, Vassilakopoulos T, Lymberis A, Roussos C, Milic-Emili J: Expiratory flow limitation and intrinsic positive end-expiratory pressure at zero positive end expiratory pressure in patients with adult respiratory distress syndrome. Am J Respir Crit Care Med 2000, 161:1590-1596.

5. Kondili E, Prinianakis G, Athanasakis H, Georgopoulos D: Lung emptying in patients with acute respiratory distress syndrome: effects of positive end expiratory pressure. Eur Respir J 2002, 19:811-819.

6. Rylander C, Tylén U, Rossi-Norrlund R, Herrmann P, Quintel M, Bake B: Uneven distribution of ventilation in acute respiratory distress syndrome. Critical Care 2005, 9:R165-R171.

7. Milic-Emili J, Torchio R, D’Angelo E: Closing volume: a reappraisal (19672007). Eur J Appl Physiol 2007, 99:567-583.

8. Kropski JA, Fremont RD, Calfee CS, Ware LB: Clara cell protein (CC16), a marker of lung epithelial injury, is decreased in plasma and pulmonary edema fluid from patients with acute lung injury. Chest 2009, 135:1440-1447.

9. Muscedere JG, Mullen JBM, Gan K, Slutsky AS: Tidal ventilation at low airway pressures can augment lung injury. Am J Respir Crit Care Med 1994, 149:1327-1334.

10. D’Angelo E, Pecchiari M, Baraggia P, Saetta M, Balestro E, Milic-Emili J: Lowvolume ventilation causes peripheral airway injury and increased airway resistance in normal rabbits. J Appl Physiol 2002, 92:949-956.

11. D'Angelo $E$, Pecchiari $M$, Gentile $G$ : Dependence of lung injury on surface tension during low-volume ventilation in normal open-chest rabbits. J Appl Physiol 2007, 102:174-182.

12. D'Angelo E, Koutsoukou A, Della Valle P, Gentile G, Pecchiari M: Cytokine release, small airway injury, and parenchymal damage during mechanical ventilation in normal open-chest rats. J Appl Physiol 2008, 104:41-49.

13. Tsuchida S, Engelberts D, Peltekova V, Hopkins N, Frndova H, Babyn P, McKerlie C, Post M, McLoughlin P, Kavanagh BP: Atelectasis Causes Alveolar Injury in Nonatelectatic Lung Regions. Am J Respir Crit Care Med 2006, 174:279-289.

14. James A, Wenzel S: Clinical relevance of airway remodelling in airway diseases. Eur Respir J 2007, 30:134-155.

15. Bernard GR, Artigas A, Bringhan KL, Carlet J, Falke K, Hudson L, Lamy M, Legall JR, Morris A, Spragg R: The American-European Consensus Conference on ARDS: definition, mechanisms, relevant outcomes, and clinical coordination. Am J Resp Crit Care Med 1994, 149:818-824.

16. In Katzenstein and Askin's Surgical Pathology of Non-Neoplastic Lung Disease. Volume 13 in Major Problems in Pathology. Edited by: Katzenstein A-LA. Philadelphia: Saunders; 2006:

17. Weigert C: Über eine methode zur farbung elastischer fasern. Zentralb/ Allg Pathol Anat 1898, 9:289-292.

18. Araujo BB, Dolhnikoff $M$, Silva FFL, Elliot J, Lindeman JHN, Ferreira DS, Mulder A, Gomes HAP, Fernezlian SM, James A, Mauad T: Extracellular matrix components and regulators within the airway smooth muscle in asthma. Eur Respir J 2008, 32:61-69.

19. Matsushita MM, Silva LFF, Santos MA, Fernezlian S, Schrumpf JÁ, Roughley P, Hiemstra OS, Saldiva PHN, Mauad T, Dolhnikoff M: Airway proteoglycans are differentially altered in fatal asthma. J Pathol 2005, 207:102-110.

20. Mauad T, Silva LF, Santos MA, Grinberg L, Bernardi FD, Martins MA, Saldiva PH, Dolhnikoff M: Abnormal alveolar attachments with decreased elastic fiber content in distal lung in fatal asthma. Am J Respir Crit Care Med 2004, 170:857-862

21. Carroll N, Elliot J, Morton A, James A: The structure of large and small airway in nonfatal and fatal asthma. Am Rev Respir Dis 1993, 147:405-410.

22. Ghadiali SN, Gaver DP: Biomechanics of liquid-epithelium interactions in pulmonary airways. Respir Physiol Neurobiol 2008, 163:232-243.

23. Copland IB, Kavanagh BP, Engelberts D, McKerlie C, Belik J, Post M: Early changes in lung gene expression due to high tidal volume. Am J Respir Crit Care Med 2003, 168:1051-1059.

24. Ghadiali SN, Gaver DP: An investigation of pulmonary surfactant physicochemical behavior under airway reopening conditions. J Appl Physiol 2000, 88:493-506.

25. Martin C, Papazian L, Payan MJ, Saux P, Gouin F: Pulmonary fibrosis correlates with outcome in adult respiratory distress syndrome. A study in mechanically ventilated patients. Chest 1995, 107:196-200.

26. Liebler JM, Qu Z, Buckner B, Powers MR, Rosenbaum JT: Fibroproliferation and mast cells in the acute respiratory distress syndrome. Thorax 1998, 53:823-829.

27. Krein PM, Sabatini PJB, Tinmouth W, Green FHY, Winston BW: Localization of insulin-like growth factor-i in lung tissues of patients with fibroproliferative acute respiratory distress syndrome. Am J Respir Crit Care Med 2003, 167:83-90.

28. Negri EM, Montes GS, Saldiva PHN, Capelozzi VL: Architectural remodelling in acute and chronic interstitial lung disease (ILD): fibrosis or fibroelastosis? Histopathology 2000, 37:393-401.

29. Limper $\mathrm{AH}$, Roman J: Fibronectin: a versatile matrix protein with roles in thoracic development, repair and infection. Chest 1992, 101:1663-1673.

30. Bensadoun ES, Burke AK, Hogg JC, Roberts CR: Proteoglycan deposition in pulmonary fibrosis. Am J Respir Crit Care Med 1996, 154:1819-1828.

31. Demoule A, Decailliot F, Jonson B, Christov C, Maitre B, Touqui L, Brochard L, Delclaux C: Relationship between pressure-volume curve and markers for collagen turn-over in early acute respiratory distress syndrome. Intensive Care Med 2006, 32:413-420.

32. Bai A, Eidelman DH, Hogg JC, James AL, Lambert RK, Ludwig MS, Martin J, McDonald DM, Mitzner WA, Okazawa M, Pack RJ, Paré PD, Schellenberg RR, Tiddens HAWM, Wagner EM, Yager D: Proposed nomenclature for quantifying subdivisions of the bronchial wall. J Appl Physiol 1994, 77:1011-1014.

33. Pugin J, Verghese G, Widmer MC, Matthay MA: The alveolar space is the site of intense inflammatory and profibrotic reactions in the early phase of acute respiratory distress syndrome. Crit Care Med 1999, 27:304-312.

34. Fligiel SEG, Standiford T, Fligiel HM, Tashkin D, Strieter RM, Warner RL, Johnson K, Varani J: Matrix metalloproteinases and matrix metalloproteinase inhibitors in acute lung injury. Human Pathology 2006, 37:422-430.

35. Granja C, Morujão E, Costa-Pereira A: Quality of life in acute respiratory distress syndrome survivors may be no worst than in other ICU survivors. Intensive Care Med 2003, 29:1744-1750.

36. Neff TA, Stocker R, Frey HR, Stein S, Russi EW: Long-term Assessment of Lung Function in survivors of Severe ARDS. Chest 2003, 123:845-853.

37. Heyland DK, Groll D, Caeser M: Survivors of acute respiratory distress syndrome: relationship between pulmonary dysfunction and long-term health-related quality of life. Crit Care Med 2005, 33:1549-1553.

38. Broccard AF, Shapiro RS, Schimtz LL, Ravenscraft SA, Marini JJ: Influence of prone position on the extent and distribution of lung injury in a high tidal volume oleic acid model of acute respiratory distress syndrome. Crit Care Med 1997, 25:16-27.

39. Takeuchi M, Goddon S, Dolhnikoff M, Shimaoka M, Hess D, Amato MBP, Kacmarek RM: Set positive end-expiratory pressure during protective ventilation affects lung injury. Anesthesiology 2002, 97:682-692

40. Amato MB, Barbas CS, Medeiros DM, Magaldi RB, Schettino GP, LorenziFilho G, Kairalla RA, Deheinzelin D, Munoz C, Oliveira R, Takagaki TY, Carvalho CR: Effect of a protective-ventilation strategy on mortality in the acute respiratory distress syndrome. N Engl J Med 1998, 338:347-354.

41. Terragni PP, Rosboch G, Tealdi A, Corno E, Menaldo E, Davini O, Gandini G, Herrmann P, Mascia L, Quintel M, Slutsky AS, Gattinoni L, Ranieri VM: Tidal 
Hyperinflation during low tidal volume ventilation in acute respiratory distress syndrome. Am J Respir Crit Care Med 2007, 175:160-166.

42. The Acute Respiratory Distress Syndrome Network: Ventilation with lower tidal volumes as compared with traditional tidal volumes for acute lung injury and the acute respiratory distress syndrome. N Engl J Med 2000, 342:1301-1308.

43. Rouby J, Lherm T, Martin de Lassale E, Poète P, Bodin L, Finet JF, Callard P, Viars P: Histologic aspects of pulmonary barotrauma in critically ill patients with acute respiratory failure. Intensive Care Med 1993, 19:383-389.

doi:10.1186/cc9401

Cite this article as: Morales et al:: Small airway remodeling in acute respiratory distress syndrome: a study in autopsy lung tissue. Critical Care 2011 15:R4.

Submit your next manuscript to BioMed Central and take full advantage of:

- Convenient online submission

- Thorough peer review

- No space constraints or color figure charges

- Immediate publication on acceptance

- Inclusion in PubMed, CAS, Scopus and Google Scholar

- Research which is freely available for redistribution

Submit your manuscript at www.biomedcentral.com/submit
C BioMed Central 